\title{
Gambling as a perceived societal problem: A preliminary analysis of attitudes and experiences of frequent/compulsive gamblers
}

\author{
Kimisha Bhaga and Wilfred I. Ukpere* \\ Department of Industrial Psychology and People Management, Faculty of Management, University of Johannesburg, \\ South Africa. \\ Accepted 14 September, 2012
}

\begin{abstract}
The main objective of this study is to determine the extents to which gambling affects individuals who frequently indulge in gambling, in order to understand their attitudes and experiences. To achieve this objective, a qualitative interview was undertaken. This required face-to-face interaction with the interviewees. Responses were tape recorded for the purposes of authenticity, credibility, transcription and analysis. The interviews were conducted in an environment most suitable and comfortable for both the researchers and the respondents. 5 participants, all of which are frequent gamblers' participated in the study. The participants displayed different personalities but one characteristic that they all had in common was a secured lifestyle, however, they are still oblivious to the dangers inherent in gambling. Some of them are of the view that they are not yet addicted and as such not at risk of becoming compulsive gamblers. Some of them are wealthy and therefore, their responsibilities are not an issue. Majority of them claimed to be seasoned gamblers based on the experiences that unfolded during the interview. The personalities of the gamblers suggest that majority of them are extroverts, however some gamblers are more mature than others and display more responsible behaviour than others. It is proposed in this treatise that gamblers should be educated more about the dangers of gambling. Casinos should perhaps monitor the behaviours of their frequent gamblers and endeavour to help them if their gambling becomes a menace. Compulsive or pathological gamblers should limit their access to cash, admit to their problem and seek help through family and professional counsellors.
\end{abstract}

Key words: Gambling, gamblers, frequent, compulsive, experiences, pathological.

\section{INTRODUCTION}

This article has been conducted to examine the attitudes, behaviours and experiences of frequent gamblers in society. Many people gamble as a form of recreation. However, some people do so in the hope of some financial gains, which they do not possess. To some, gambling has become a career, of which certain individuals have become professionals in the act (Campbell and Lester, 1999). For the fact, most of the gamblers are wealthy; gambling therefore becomes a skill to be mastered. However, to others it is usually a quick, easy and entertaining way to earn extra money without

\footnotetext{
${ }^{*}$ Corresponding author. E-mail: wiukpere@uj.ac.za.
}

dumbluck. Gambling to most is perceived as harmless, the effort and discipline involved in working at a secular job (Cosgrave, 2006). Gamblers risk losing their hardearned money to win some more based on sheer luck until people become compulsive gamblers (Campbell and Lester, 1999). Gambling affects adolescents, adults, the elderly, the wealthy and the poor. It is a social problem which many are oblivious to, which is the reason why it makes for such an intriguing research focus.

The motivation behind this study stems from one of the author's experiences with some of his family members who also engage in gambling and are victims of the problems associated with gambling. Gambling brings about negative personality traits such as irresponsibility, selfishness, isolation, boastfulness, greed, desperation 
(Riconda, 1995), just to mention a few. Hence, undertaking a research on gambling is important, since it will help people to understand better the repercussion of gambling addiction and enable frequent gamblers to become aware of the risks associated with gambling.

The article outlines include an introduction, a problem statement and research question and objectives, whereby the topic of gambling as a societal problem will be defined. This will be followed by a literature review. The process of the research methodology will be outlined and a thorough analysis will be conducted based on the findings of the research. Thereafter, the research question will be answered and recommendations will be proposed on how to reduce the effects of gambling on gamblers and society in general.

\section{Problem statement}

Frequent and compulsive gamblers spend exorbitant amount of money on gambling. They have an urge to gamble and get an adrenalin-rush/high while gambling. This feeling usually excites and satisfies the gambler, especially when they are winning. Gamblers are always determined to win, which keeps them gambling until they become addicted to it. Some people have great control and can resist the temptation of gambling. Evidently, these individuals are usually those who have been instilled with values and morals, which stem from their upbringing that fosters a sense of responsibility. However, there are many who are vulnerable and cannot control their urges to earn additional income from any other sources. These individuals are consumed with greed to make additional money at all cost, which makes them to become selfish and ignore any call to order and responsibility.

\section{Research questions}

The previous build-up has led to the following research questions for this study which relates to the gaming world and gamblers:

1. What are the attitudes and behaviour of these frequent gamblers towards gambling and what are the reasons that keep them in gambling?

2. What are the feelings and experiences of gamblers while gambling and how do they generate the money for gambling?

3. To what extent are gamblers aware that gambling can have an adverse effect on their obligation towards their families and society?

4. To what extent are gamblers aware that gambling is an increasing societal problem that affects adolescents, adults, the elderly, the wealthy and the poor?

\section{Objectives of the study}

The objectives of the study are:

1. To observe the attitudes and behaviour of these frequent gamblers towards gambling in order to establish what keeps them in the act.

2. To examine the feelings and experiences of gamblers while gambling and establish how they generate the money for gambling.

3. To understand whether they are aware that gambling can have an adverse effect on their obligation towards their families and society.

4. To establish whether gamblers are aware that gambling is an increasing societal problem that affects adolescents, adults, the elderly, the wealthy and the poor.

\section{Significance of the study}

This topic is very interesting and significant in our lives, because many people do not understand how serious the problem of gambling can be, because it involves money which is imperative for peoples' physical existence or a means to an end. Losing money should not be an option or risk. It is also significant as it lends itself to equip psychologists and psychiatrist in exercising therapy efficiently, since each affected gambler's attitude will differ. The people who interact daily with these gamblers will have a resource to deal with their respective problems, alleviating, if not eradicating the burden. It is also an interesting topic, because it cannot be contained in a neat package as there are many anomalies, which could elude the most astute scholar.

\section{LITERATURE REVIEW: THE WORLD OF GAMBLING}

The gambling world may be described as a magical one. Cosgrave (2006: 1) posited: "Successes and failures, thus arising from causes that are unanticipated, generally unintelligible and seemingly dependant on chance, predispose the bourgeois to the gambler's frame of mind...The gambler, however is a supremely superstitious being". Gamblers depend on their luck because whether they win or lose is an uncertain outcome. Before 1950, gambling was not fully accepted by the state. However, many forms of gambling or games were legalized in America. Thereafter, the state conceived that gambling would generate revenue without increasing taxes (Blakely, 1984: 12 to 21), and therefore made it legal.

Legalised gambling as we know it today has been an increasing trend all over the globe (Barnhard et al., 2006). Gambling is no longer a disreputable activity anymore and has become a popular game. Much research about gambling has been conducted in North America, Canada and Europe, presumably because their gambling industries are world renown, very big and yield 
an ample amount of socio economic gain (Frey and Eadington, 1984; Frey et al., 1998). Literature shows that South African boasts an array of casinos with other avenues for gambling. For example, Sun City, Emperors Palace, Monte Casino, Sibaya casino, Suncoast casino, Gold Reef City, Turfontein racecourse, to mention a few, have various types of gambling apparatuses.

\section{Various types of gambling}

In a casino there are many types of games people play. There are many different slot machines to choose from or you can gamble your money at a table playing poker, blackjack or roulette. At tables the stakes are usually very high, but at slot machines there are different bets and certain slot machines have lower bets than others. For example, you can gamble at a slot machine for as little as 5 cents a bet or you could choose a more expensive slot machine where the minimum bet could be R5, 00. Other types of gambling include Bingo, Keno, lottery tickets, sports betting and horse betting (Riconda, 1995: 27 to 46). Another type of gambling that has become popular recently is internet or online gambling. Many people find these games intriguing and exciting and dig deep into their pockets to have a go at it.

\section{Compulsive gambling as a social problem}

Gambling to many has become an addiction. Riconda (1995: 153) suggests that "in areas where more forms of gambling are legal, the incidence of problem and pathological (compulsive) gambling is also higher". Compulsive or pathological gambling can be defined as a serious, on-going failure to stop or stay away from the urge to gamble. Pathological gamblers get adrenalin while gambling. This addiction makes them oblivious to more important things that they need to do, to such an extent that they will last without sleeping or going to the bathroom and even tend to suppress their hungers (Riconda, 1995: 154).

The foregoing is merely one concept of what compulsive gambling entails. There are many other concepts which dig deeper and bring about technical variance to give us insight to other researchers theoretical ideas, principles or beliefs about gambling as an addiction. Some of these literatures are also important as each theorist or researcher espouses their stance as far as the attitudes and experiences of frequent/compulsive gamblers are concerned.

\section{The attitudes and experiences of frequent/ compulsive gamblers}

Gamblers gradually become addicted according to
Skinner's psychological theory of operant conditioning and reinforcement. The moment a gambler receives a monetary reward from gambling, their behaviour is reinforced and they feel the need to keep on gambling to gain a positive outcome. They want to experience the thrill and euphoria that comes with a win. These gamblers also gamble to be noticed by others as a way of earning a status. Gambling is not only appealing because of its chance of luck and winning but in a casino a gambler is also drawn in by the colour and flashy glittery lights on slot machines or even watching a roulette wheel spin in anticipation. The atmosphere that a casino creates has a big impact on gamblers.

Gambling becomes addictive when a gambler keeps thinking that he/she will win if they keep on trying even after losing because there is always a belief that they lost by a 'near miss'. A good example of explaining a 'near miss' is when a slot machine shows a triple line of symbols such as 7's, which is a win. However, if two of the same symbols are in the row, the gambler would be determined to win and continues to play believing that 3 of the same symbols will be displayed. The concept of the 'near miss' creates an urge to gamble more, which is dangerous as the gambler is constantly losing perceives it as almost winning (Griffiths and Parke, 2004: 407 to 408).

Some people have great control and know their limits to gambling. This set of individuals sees it as form of recreation. However, there are many out there who are vulnerable and cannot control their urges and keep their money in their pockets for better use. As mentioned earlier in literature, those who have been instilled with values and morals which stem from their upbringing are more responsible in terms of participating in gambling. Some others are consumed with the greed of making additional money, which becomes their ultimate desire and goals. They may become selfish and neglect some of their responsibilities, thereby suffering emotionally, physically and psychologically (Riconda, 1995: 155 to 159). They may not be the only ones who suffer but their families go through rough times as well.

\section{Phases in the development of gambling addiction}

The first phase is when a person steps into the world of gambling and sees it as a way to reducing stress and forget about his/her pressures or challenges at work or at home. The next phase is the chasing phase where the gambler starts becoming obsessed with gambling and he/she feels ashamed and guilty when they lose but still bet large sums of money to win. The gambler soon becomes poor and craves to gamble more to the extent that he/she can do anything including crime (stealing, cheque forgery) to get money or borrow from others. This is the final phase called the desperation phase and this is when they need to seek serious help because they bring themselves down and feel useless (Abbott, 1999: 1). 


\section{Gambling and gaming addictions in adolescence}

Adolescents may be more susceptible to pathological gambling than adults because young people tend to be more vulnerable to the negative consequences of gambling than adults" (Griffiths, 2002: 5). Research has shown that there are 3 types of gambling which are predominant among adolescents, namely lotteries, scratch cards and fruit machines. Despite whatever name it may be called, gambling holds many negative consequences for adolescents (Coventry and Brown, 1993). For example, an adolescent who starts to enjoy gambling at fruit machines is bound to bunk school to go for gambling and might end up stealing money or use their allowance or lunch money to gamble. Their school grades may suffer and they become delinquents.

Based on empirical research literature by Griffiths (2002), adolescents who engage in gambling are inline of becoming pathological gamblers. Majority of them are males, whose parents are also frequent gamblers. They also gamble on their own and chase losses. They have as well experienced the excitement that comes with winning. They use gambling to gain popularity from friends. They are from lower social classes and have other addictions like smoking or drinking. They come from homes where there are conflicts.

\section{Suicidal behaviour from pathological gamblers}

There is a definite elevated level of suicide amongst gamblers. Pathological gamblers frequently take their lives because they cannot deal with their financial and family problems. They start feeling hopeless and isolate themselves from everyone instead of getting help. According to some statistics, the most suicidal of gamblers were men. There were $42 \%$ of suicide attempts by pathological gamblers in 2002 (Pfuhlmann and Schmidtke, 2002: 257 to 260). "Accordingly, a suicide attempt itself would be a kind of game in which literally one's own life is put at stake. Here, the element of risktaking in view of an uncertain outcome would be of prime importance" (Pfuhlmann and Schmidtke, 2002: 260). In other words, they literally "gamble their lives away".

\section{Social responsibility tools in online gambling}

A social responsibility tool called play scan was designed by the Swedish gaming company. Play Scan's objective is to prevent people who gamble online from becoming compulsive gamblers. "The tool measures increases and/or decreases of players' gaming behaviour and uses a "traffic light" identification system" (Griffiths et al., 2009: 413). Play scan simply gives a green light of approval to a person who does not show signs of becoming a pathological gambler, yellow would signal risky gaming
And remind the player not to get carried away. If a player displays a gambling problem then a red signal is shown. This is gambling at its best, taking care of your customer is a good ethic and gesture. Hopefully, systems like these could be adopted for other gambling services in future. However, some sections argue that this system may decrease a player's excitement and make them irritable. It can also have negative impacts on the gambling business.

\section{Gambling treatment}

In Canada, a 12 Step recovery programme and outpatient programmes were introduced to help pathological gamblers understand what they suffer from and how best to recover from it. Three important things are drilled into participants in counselling namely, limited access to cash, get honest with loved ones and find a support group. People can recover without formal treatment by admitting to their gambling problem with a desire to sort it out (Canadian Medical Association, 2008: 122 to 127).

\section{Gambling and religion}

Gambling for many religions is prohibited. Jewish, Muslims and Christians are advised not to gamble. Even though gambling is popular among many, gambling to many religions is a form of greed, since it is an attempt to make money through the losses of others. The Bible does not discuss gambling in detail but it provides us with principles that determine how God views gambling. The Bible strongly condemns greed by warning that "no greedy person would have any inheritance in the Kingdom of God (Ephesians 5: 5)".

In a nutshell, much of the literature consulted reflected the same views on what compulsive gambling is all about. Some literature might be older than others but similar knowledge is shared. Researchers have not investigated much on the types of people that are involved in gambling. There is a need to fill that gap. Some rich people are more susceptible to becoming pathological gamblers, because they may not have many responsibilities equal to their wealth. Poor people can be drawn into gambling in the hope of gaining more money to support their families but it is more likely that they may not indulge in gambling because they have to make a means with the little income that they have.

Researchers also have note investigated much about raffle tickets as fundraisers at schools or funding charities, healthcare, orphans and other initiatives raise fund through gambling. Gambling may as well have some benefits but it has not been further explored. To round up, gambling can be addictive and people need to learn to control their urges and know their limits because being 
Table 1. Interview schedule.

\begin{tabular}{cl}
\hline $\mathbf{S} / \mathbf{N}$ & Questions \\
\hline 1 & Are you employed? If you are, then what is your occupation? If not, why? \\
2 & On estimate, how many times a month do you gamble? \\
3 & When did you start gambling? \\
4 & What games do you gamble your money on? (for example. slot machines, roulette, poker, etc.) \\
5 & If you win money from gambling, do you collect your earnings and stop or do you continue playing and why? \\
6 & What do you experience or feel whilst gambling? \\
7 & If you are gambling and you lose your money, what do you usually do? \\
8 & Have you ever had any financial problems because of gambling? If yes, were you able to overcome it? Elaborate \\
9 & How does your family feel about your gambling? \\
10 & Would you ever borrow/loan money to gamble? \\
11 & Have you ever gambled to such an extent that you somewhat neglected your work or family or obligations because \\
12 & of gambling? Elaborate \\
13 & Do you take note of the time while you are gambling and ensure that you get enough sleep and nutrition?
\end{tabular}

Authors' Fieldwork (2012).

addicted to gambling is just as bad as being addicted to drugs.

\section{RESEARCH METHODOLOGY}

The qualitative research method was adopted to examine the attitudes and experiences of frequent gamblers in the society. The qualitative interview questionnaire was constructed as a means for the interview and supported by the researchers own observations and other pertinent literatures. With this approach, research is usually conducted within a natural setting of social actors, which is why the researcher adopted a face-to-face interaction with respondents. The main objective of using the qualitative method is to obtain an in depth or thick descriptions and understandings about what the frequent gambler thinks based on their experiences. We refer to this as the "insider/emic view". Qualitative research focuses on studying phenomena as a process over time which is important as the theories of gambling would always change with time. A researcher would make observations and list their findings based on their interpretive understanding of social action in terms of the ideographic motive and not by generalising (Babbie et al., 2001).

Qualitative research is also inductive and results most of the time in the generation of a new hypotheses and theories. With this interview schedule, a researcher creates a close bond with the subject and shows interest in what the subject tells them to generate truthful and credible inter-subjectivity/responses. Table 1 shows the interview schedule that was used for this study.

The research has examined the attitudes and experiences of frequent gamblers at Gold Reef City Casino, situated in Johannesburg, Gauteng. Any person aged 18 and older who is identified as frequent gamblers will be used as the unit of analysis and can participate in the qualitative interviews which include questions based entirely on gambling. Only 5 participants were willing to participate in the study.

One of the authors had the privilege to tag along to Goldreef City Casino with some relatives, who are frequent gamblers. They were able to point out people who are regulars in the casino, which enabled the author to approach them to request their participation in the interview. The researcher was able to interview three gamblers in the casino in the prive lounge (the fancy area where high rollers gamble). However, the other two gamblers had invited him to their homes to conduct the interview.

\section{DATA ANALYSIS AND FINDINGS}

This section deals with the data analysis, which helps to interpret how and what the various respondents mentioned in terms of their attitudes and experiences towards gambling (Table 2).

\section{Similarities of respondents}

All the respondents come from wealthy homes and have a secure lifestyle and that was a main similarity amongst them. The wealthier frequent gamblers were interviewed as opposed to those frequent gamblers who walk around casinos begging for money to gamble with and chronically suffering from gambling addiction.

From the five participants, three of them (respondents $1,3$ and 4$)$ were in the same age category (+/- 50 years old). Their attitudes while gambling are the same in the sense that if they win money they do not collect their earnings but continue playing. They have all been to various different places to gamble and have had many experiences with gambling throughout their lives. It is very interesting to hear about their experiences, because although they are Gold Reef City regulars they have visited almost every casino they possibly could. They all have a passion for gambling from our findings and they are well seasoned gamblers who know exactly how to play the games. All five respondents are very skilled when it comes to their strategies when they are gambling. 
Table 2. Research themes.

\begin{tabular}{|c|c|}
\hline $\mathbf{S} / \mathbf{N}$ & Themes \\
\hline 1 & $\begin{array}{l}\text { Boastfulness: This was a theme that was prominent throughout my study. Some of the respondents } \\
\text { were more boastful than others, but gamblers in general seek attention and have an air about } \\
\text { themselves, according to the literature I consulted, gamblers gamble to get noticed by others and try } \\
\text { to gain status (Griffiths and Parke 2004: } 407 \text { to 408). }\end{array}$ \\
\hline 2 & $\begin{array}{l}\text { Responsibility: This is an important theme, because without a sense of responsibility, a gambler is at } \\
\text { risk of becoming a compulsive gambler. Four of my respondents all displayed irresponsible } \\
\text { behaviour when it came to the amount of money and time they spend on gambling. However, the } 1 \\
\text { respondent insisted that he knew his limits. They did not feel the need to be responsible, because } \\
\text { they either have back-up plans or they are wealthy enough to spend their money as they please. } \\
\text { However, they don't forget their responsibilities entirely they do show that they care immensely for } \\
\text { their families especially the respondents, Fazila, Bugsy and Nielie. Their maturity levels are high } \\
\text { because they around } 50 \text { years of age. }\end{array}$ \\
\hline 3 & $\begin{array}{l}\text { Secure lifestyles: All the respondents have a secure lifestyle. They are not at a big risk of becoming } \\
\text { compulsive gamblers because of their wealth or good family support system. }\end{array}$ \\
\hline 4 & $\begin{array}{l}\text { Recreation: All the respondents clearly gamble for the fun of it. They do not need the extra money } \\
\text { but enjoy spending time at casinos and winning and they are well seasoned gamblers. They did not } \\
\text { go through any major financial problems. }\end{array}$ \\
\hline 5 & $\begin{array}{l}\text { Casinos: Casinos lure people in, they are drawn in by the extravagant set out of the casino and the } \\
\text { many luxuries it offers gamblers to keep them there. The respondents mention how the casinos } \\
\text { provide for them and how convenient it is for them to get accommodation, food and beverages. }\end{array}$ \\
\hline
\end{tabular}

Authors' Fieldwork (2012).

Even though gambling is about chance and luck they take their gambling quite seriously. They all began gambling at a very young age. Respondents 1 and 2 are both very cool and calm and extremely kind and humble. They both were very honest and were straight forward. They were not snobbish, pompous or boastful. Although respondent 1 is 54 years old and respondent 2 is 26 years old they both are very mature and educated. From observation, they may not be at any risk of becoming compulsive gamblers. Respondents 3,4 and 5 come across as very boastful.

Respondent 3 boasted about owning 2 race horses, placing $3^{\text {rd }}$ in a huge roulette competition held in Sun City and winning over R50 000 on a poker machine. Respondent 4 boasted about her overseas trips and about having the best of cars, jewellery and clothes. Respondent 5 boasted about his good looks and his car. They are lucky players and spend a lot and win quite a bit as well. The 3 of them do not restrict themselves to any limits while spending money.

Roulette seems to be a popular game and all the respondents have mentioned that they spend their money on roulette. When the respondents were asked how they feel while they are gambling, a common response was the feeling of excitement. According to literatures reviewed gamblers feel a thrill and get an adrenalin rush, which harmonises with our research findings. Another similarity amongst the respondents is that they all exclaim that they would never take a loan or borrow money to satisfy their gambling urge. All the respondents do not have or experience financial problems. Respondents 1, 2, 3 and 4 share the similarity that their families are fine with them gambling and explained that they let their families tag along to have fun at the casino as well. They do splash out on family and friends with their winnings.

\section{Differences of respondents}

When respondents were asked about whether they were employed or not, different responses were given. Respondent 1 is an Educator. Respondent 2 is an Insurance Claims Agent at Wesbank. Respondent 3 is unemployed because of injuries sustained in an accident and bad health. Respondent 4 is self-employed and has a framing business. Respondent 5 is a tertiary student pursuing a career in entrepreneurship at the University of South Africa (UNISA). Knowing about these gamblers occupations is important as it gives us an idea about their financial status and tells us who has more obligations in their workplace than others and who has to go to work. For example, Respondent 4 is running her own business so she could be gambling longer than the others because she does not have to worry to answer to an employer or manager if she is not productive at work. She earns a lot and makes it seem like she has nothing to worry about. 
However, respondent 5 is a student and should be spending more time studying, instead he is gambling. Respondent 1 is an educator so her income is average but she saves well in other accounts that she cannot touch unless she desperately needs that money. Respondent 2 works in a bank and this may be where his responsible nature stems from. He knows how best to handle his income. Respondent 3 does not work but he has a good support system and he still has enough money from the business he had. These differences tell us a lot about how responsible they have to be and how gambling could become a huge distraction in more important areas of their lives. Another difference is that this study was aimed at any frequent gamblers so there are both male and female respondents.

The respondents might be similar in that they all play roulette but they differ in the other games they play. Some of them like to play slot machines and blackjack or poker. Respondent 3 started gambling by playing Fafi (a Chinese game about lucky numbers). Respondents 2 and 3 are also different in the sense that they gamble their money on horse racing. They all differ in terms of the amount of times they go to casinos to gamble. Respondent 1 says that she goes every weekend and sometimes on a week night. Respondent 2 says that he goes about twice a month. Respondent 3 says that he goes almost every day if it is possible. Respondent 4 says that she goes every Friday or Saturday night. Respondent 5 says that he goes about 8 times a month. Respondent 1 and 3 were different in the sense that they wanted to be interviewed in the comfort of their homes. Respondents 2, 3 and 5 differed by wanting to remain anonymous and gave me a pseudonym to use instead of revealing their true identities(hence we have used * to show the respondents with pseudonyms) there and all of them were males. During the interview process, some of the respondents had no inhibitions and opened up, but with others, the researcher had to probe a little more to get more insight of their gambling experiences.

\section{Observations}

\section{Respondent 1: Fazila. M}

The participant was very responsive, patient and kind. It was enjoyable to interview her because she opened up without any hassle and answered every question with ease. The questions probed in the interview gave me more insight about her gambling experiences. She was honest about many things that many frequent gamblers would not admit to. She admitted to feeling bad about not following guidelines of her Islamic religion that does not permit gambling. She spoke of neglecting her family and losing a sense of time and responsibility while gambling. It was very interesting to find out how she ensured that she would not have financial problems by securing money in other accounts. The interview lasted about half an hour and was definitely a successful one.

\section{Respondent 2: White Rabbit Soldier*}

On meeting this participant, he was very cool and calm but kept asking how long it would take. He was assured that it would not take very long. He wanted to make interviewer comfortable more than the interviewer wanted to make him. He offered to order a choice beverage and insisted that the research should have something. What was interesting was when that he always summoned a waiter by clapping his hands twice. The waitress immediately came and asked him what he would like to order (The casino does this so that the gambler remains focused on the game and spends more money). The pseudonym he chose to use is actually his disc jockey (DJ) identity, which is quite interesting. In his spare time, he gets some pocket money from DJ'ing at parties. His answers were straight forward and he did not tell many stories, although when it was probed about how he started gambling he opened up and mentioned about how his dad would sneak him into a casino when he was a minor. $\mathrm{He}$ came across as quite responsible and mature and there is no reason to think that his frequent gambling behaviour could affect him.

\section{Respondent 3: Bugsy*}

The respondent was very busy playing roulette when the researcher wanted to approach him. When the interviewer got the chance to speak to him, he agreed to be a participant and said that he would like to do it in the comfort of his own home. An arrangement was therefore made to conduct the interview at his home. He was reading the newspaper while the research posed his questions to him, but he answered exactly how he wanted and did not have any inhibitions. From his responses one could tell that he was indeed a seasoned gambler who knew a lot about gambling from his past experiences. He was very cold when he spoke about who always had his back. One could also tell he was let down by people who he took as friends who just used him for his money and forgot about him when he needed them the most, like they say "When days are dark, Friends are few". He came across as a very boastful kind of person, but it was very interesting to interview him. He also was interested in why the interview was being conducted and detailed explanation was given to on what it was all about. He said that it was good that I chose an unusual topic like gambling because he knows many people that have lost their lives and homes to gambling.

\section{Respondent 4: Nielie. P}

The respondent was very friendly and didn't hesitate to answer the interview. In fact she was excited to be 
interviewed. She was very responsive and she had lots to tell me about her experiences. She is extremely wealthy and gambling for her is something she enjoys without any stress. She is a seasoned gambler and is very well known at Gold Reef. While she was being interviewed many people stopped to greet her and one could tell she was definitely very popular. She was very beautiful and she was adorned with lots of stunning jewellery. She boasted a lot but one could tell by the way she answered that even though she gambles, her family is most important to her. She even offered the researcher some money to gamble with her after the interview but he declined for ethical reasons. She came across as a person that has nothing to lose.

\section{Respondent 5: Player*}

The respondent was excited to be interviewed. He was very flirtatious and boasted a lot but nevertheless, he was funny and kind. He is definitely from a wealthy family and he is very spoilt. He was dressed in expensive brand named clothing from head to toe. He was a little imamture when answering the questions but he got straight to the point and was honest about many things. He thought the interview was quite interesting and asked about what the researcher was studying and said that sometimes he sees people at the casino who actually ask people to borrow them money without feeling any shame. It is presumed that the researcher needs to speak to the better bunch of frequent gamblers, not the people who are pathological gamblers. This respondent needs to learn responsibility though. Some important extract from the respondents response with regards to their experiences in gambling are as follows:

1. How does your family feel about your gambling? In response to the previous question, the first interviewee stated that initially it was exciting for them as a family but then their children realise that sleep is lost and they become uncomfortable and show their disapproval. Therefore, she felt it was better to leave them behind and go alone with her husband. This move places a strain in the relationship with her children. This is a useful statement because in the literature review it was stated that gambling does not only harm the gambler but it puts a big strain on the family. This shows that gamblers would actually leave their children behind to go for gambling instead of not going at all or leave the casino before their children get tired. In that case gambling makes people selfish as they forget what is more important.

2. Do you continue gambling when you are wining or collect your wins and leave? In response to the question the second interviewer stated that he collect his wins and stops playing. He maintained the he only plays with money that was originally invested. This respondent definitely stood out from the rest because he said if he wins money, he would take his winnings and go. He is very responsible and wise and knows his limits and the dangers of gambling beyond that limit.

3. Do you get a chance to eat anything while gambling? The third respondent answered 'yes'. He added that they are MVG gold card holders and allowed to order food and drinks while they play. According to him, those are the comforts that the casinos offer to entice people. Casinos ensure that they keep their top gamblers by catering to their needs so that they stay and keep gambling their money away.

4. At what age did you start gambling? The forth interviewee stated that she started gambling at the age of 16. She said that she looked older because she was so tall therefore no one detected her age while gambling. According to her, the security guards never asked for her identity card (ID) and she made friends with the security guards so they did not mind when she played. As a matter of fact, minors should by no means be allowed to gamble. Casinos should definitely be stricter and tighten up security. This could have robbed this young mind off her time to educate herself and not get caught up in the world of gambling.

5. Are there con artists in gambling? The fifth respondent stated that he owned two race horses. They were 'Discover the blues' and the other was 'Stage pirate'. However, due to Apartheid according to him, he was tricked by some White trainers. He said that they lied to him and told him that those horses would make lots of money for him. In 2004, he took part in a huge roulette competition in Sun City and came out $3^{\text {rd }}$. This respondent was competitive and not just any gambler. It was intriguing to find this out and also remember that with gambling comes con artists. Everyone has their strategies and gamblers must be very careful when they gamble but then again gambling is about risks, chances and luck.

\section{RECOMMENDATIONS AND CONCLUSION}

The questions and objectives of the study to an extent have been resolved. It was discovered that although all the respondents have secure lifestyles they are still oblivious to the dangers of gambling. Many gamblers in society are in denial of admitting that they have a gambling problem. Their wealth does not make them feel like they are losing much when they actually lose. Many people are involved in gambling, which is why this article lends itself to equip psychologists and psychiatrists in the efficient administration of therapy for compulsive gambling, since every gambler is different and will therefore present researchers with different patterns of behaviour, attitudes and experiences.

People who interact daily with frequent gamblers will have a resource to deal with their respective problems by alleviating or perhaps eradicate the burden. However, it is 
imperative that gambling as a societal problem gets more attention because so many people in the society are not aware of the threats it poses. Gamblers need to know when to stop and admit to their problems as well as limit their access to cash. Casinos could perhaps come up with a device that reminds gamblers about how much money they have spent while gambling. Gamblers behaviours have to be studied more because their compulsive gambling affects their family lives and their work lives. Support groups can also help compulsive gamblers to control their addictions.

\section{REFERENCES}

Abbott DA (1999). Gambling in the family: The hidden addiction. J. Fam. Soc. Stud. 6(1):1-3.

Babbie E, Mouton J, Vorster P, Prozesky B (2001). The practice of social Res. Cape Town: Oxford Univ. Press.

Barnhard BJ, Lucas AF, Jang D (2006). Responsible Gaming Device Res. Report. pp. 1-57.

Blakely GR (1984). Legal Regulation of gambling since 1950. Am. Acad. Polit. Soc. Sci. pp. 12-22.

Campbell F, Lester D (1999). The Impact of Gambling Opportunities on Compulsive Gambling. J. Soc. Psychol. 139(1):126-127.
Canadian Medical Association (2008). Gambling treatment options: a roll of the dice. Med. J. 179(2):127-128.

Cosgrave JF (2006). The sociology of risk and the gambling reader. Routledge. p. 1.

Coventry KR, Brown RIF (1993). Sensation seeking, gambling and gambling addictions. J. Addict. 88:541-554.

Frey JH, Eadington WR (1984). The Annals of the American Academy of Political And Social Sci. Gambling: Views From The Social Sci. Sage publications, inc.

Frey JH Scott A, Marc S (1998). The Annals of the American Academy of Political and Social Sci. Gambling: Socioeconomic Impacts And Public Policy. Sage publications, inc.

Griffiths M (2002). Gambling and gaming addictions in adolescence. The British Psychol. Society And Blackwell Publishing Ltd.

Griffiths M, Wood RTA, Parke J (2009). Social responsibility tools in online gambling: a survey of attitudes and behavior among internet gamblers. J. Cyber Psychol. Behav. 12(4):413-421.

Griffiths M, Parke J (2004). Gambling addiction and the evolution of the "near miss". J. Addict. Res. Theory 12(5):407-411.

Pfuhlmann B, Schmidtke A (2002). Pathological gambling and suicidal behavior. J. Suicide Res. 6(3):257-267.

Riconda A (1995). Gambling. The H.W, Wilson company. 